\title{
Multiple Retinal Anomalies in Wfs1-Deficient Mice
}

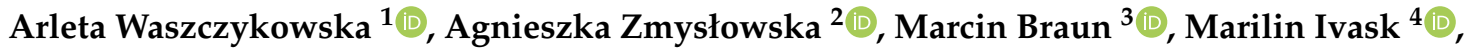 \\ Sulev Koks ${ }^{4,+}$, , Piotr Jurowski ${ }^{1}$ and Wojciech Młynarski ${ }^{5, * \mathbb{D}}$ \\ 1 Department of Ophthalmology and Vision Rehabilitation, Medical University of Łódź, \\ Żeromskiego 113 Street, 90-549 Łódź, Poland; arleta.waszczykowska@umed.lodz.pl (A.W.); \\ piotr.jurowski@umed.lodz.pl (P.J.) \\ 2 Department of Clinical Genetics, Medical University of Łódź, Pomorska 251 Street, 92-213 Łódź, Poland; \\ agnieszka.zmyslowska@umed.lodz.pl \\ 3 Department of Pathology, Medical University of Łódź, Pomorska 251 Street, 92-213 Łódź, Poland; \\ braunmarcin@gmail.com \\ 4 Department of Pathophysiology Institute of Biomedicine and Translational Medicine, University of Tartu, \\ Ravila 19, 50411 Tartu, Estonia; marilin.ivask@ut.ee (M.I.); Sulev.Koks@ut.ee (S.K.) \\ 5 Department of Pediatrics, Oncology and Hematology, Medical University of Łódź, Sporna 36/50 Street, \\ 91-738 Łódź, Poland \\ * Correspondence: wojciech.mlynarski@umed.lodz.pl; Tel.: +48-(042)-617-77-50; Fax: +48-(042)-617-77-98 \\ + Currently address: Centre for Molecular Medicine and Innovative Therapeutics, Building 390, \\ Discovery Way, Murdoch University, Murdoch, WA 6150, Australia. \\ $\ddagger$ Currently address: The Perron Institute for Neurological and Translational Science, 8 Verdun St, Nedlands, \\ WA 6009, Australia.
}

Received: 4 August 2020; Accepted: 12 August 2020; Published: 19 August 2020

check for updates

\begin{abstract}
Background: Wolfram syndrome (WFS, OMIM: \#222300) is an ultrarare autosomal recessive disorder characterized by diabetes insipidus, diabetes mellitus, optic nerve atrophy and deafness. It has been reported that the average retinal thickness in WFS patients decreases with the progression of the disease. Aim: To investigate retinal thickness and wolframin expression disorders in Wolfram syndrome 1 gene knockout (Wfs1KO) mice compared to their wild-type (WT) littermates. Materials and methods: Both bulbs with optic nerves of three mice Wfs1WT and three Wfs1KO were taken for the histopathological examination. A strain of knockout mice with mutation in exon 8 was used. Results: No expression of wolframin protein in the retina and neurodegeneration of the optic nerve of Wfs1KO mice as compared among Wfs1WT mice was observed. The mean central retinal thickness was thinner and the retinal thickness/longitudinal diameter ratio was significantly lower in hte Wfs1KO as compared to the Wfs1WT mice. In four (67\%) eyeballs of Wfs1KO mice, intra-retinal neovessels were observed. Conclusions: Wfs1KO mice retina with mutation in exon 8 present similar clinical features as patients with WFS in the form of reduced retinal thickness and neurodegeneration of the optic nerve. The presence of proliferative retinopathy observed in $\mathrm{Wfs} 1 \mathrm{KO}$ mice requires further investigation.
\end{abstract}

Keywords: Wolfram syndrome; wolframin; Wfs1; Wfs1KO mouse model; proliferative retinopathy

\section{Introduction}

Wolfram syndrome (WFS, OMIM: \#222300) is an ultrarare autosomal recessive disorder characterized by diabetes insipidus (DI), diabetes mellitus (DM), optic nerve atrophy (OA), and deafness (D)-DIDMOAD. WFS is caused by mutations in the WFS1 gene, which consists in 8 exons and is located in the fourth chromosome 4p16.1 region [1].

We have previously described that the average retinal thickness in WFS patients decreases with the progression of the disease [2]. 
To date, mutant mice lacking the $W f s 1$ gene have been generated in three independent laboratories [3-5]. One strain of mice is a conditional mutant with the specific targeting of the Wfs1 gene in pancreatic islet beta cells [5]. The other two strains were generated by inserting a neomycin-resistant cassette into the gene coding area. They only differed in the exact target region and background of the strain. Ishihara et al. traced the exon 2 gene, Kõks et al. exon 8 [2-4].

In the present study, for the first time we wanted to confirm our observations in a mouse model of Wolfram syndrome. The Wfs1-deficient mice used in the current study had the exon 8 disrupted resulting in the deletion of amino acids 360-890. In the literature, this strain is suggested as showing the most similar clinical features as patients with WFS [6].

We investigated the retinal thickness and wolframin expression disorders in Wolfram syndrome 1 gene knockout (Wfs1KO) mice compared to their wild-type (WT) littermates.

\section{Material and Methods}

The idea to perform our study came from the fact that during a routine annual examination of our nationwide cohort of WFS patients, one patient was found to have with corneal abnormalities. Thus, we conducted a corneal evaluation study in all our patients with Wolfram syndrome and in most of them we found corneal changes similar to keratoconus. In order to confirm our observations and the fact that corneal changes in this case might depend on the gene and not the species, we carried out experimental tests on a mouse model [7]. Similarly, in our previous studies, we have documented that progressive retinal thinning is present among patients with Wolfram syndrome [2]. Thus, the number of mice we evaluated in the current study was low because the design of our project has only a confirmatory not an exploratory approach.

\subsection{Animals}

Wfs1KO mice were generated by invalidating the eighth exon of the $W f s 1$ gene as described previously [4]. Experiments were performed with Wfs1KO male mice with a 129S6/SvEvTac background and their wild-type (Wfs1WT) littermates. The mice were kept in groups of eight per cage at $22 \pm 1{ }^{\circ} \mathrm{C}$ in a room illuminated artificially from 7 a.m. to 7 p.m. Tap water and food pellets were freely available.

In our approach, we decided to match the age of the mice to the median range of age of our study human cohorts (17.2-20.4 years [7-9]) according to two formulas which consider the average lifespan of laboratory mice and puberty [10]. The median age of mice of 109 days corresponds to the human age from 11.9 years (based on lifespan formula) to 29.9 years (based on puberty age formula). If we merged these two formulas, the age of our mice corresponds to 18.8 years in men, which mostly resembled the median age observed in our cohort of patients with Wolfram syndrome. Based on this calculation, we decided to scarify mice between 107 and 111 days of life to perform our study. Three mice Wfs1WT and three Wfs1KO were sacrificed at the age of $109 \pm 2$ days and both bulbs of the eye along with optic nerves were taken for the histopathological examination.

Immunohistochemical reagents for the preparation of histopathological specimens were purchased from Leica Biosystems (Wetzlar, Germany) and from Sigma-Aldrich (St. Louis, MO, USA).

Permission for this study was given by the Estonian National Board of Animal Experiments (No. 86, 4 May 2016) in accordance with the European Communities Directive of September 2010 (2010/63/EU).

\subsection{Histopathological Examination}

The bulbs of the eyes, after fixation in 10\% neutral buffered formalin for at least $24 \mathrm{~h}$ and after macroscopic evaluation, were processed into tissue blocks embedded in paraffin (FFPE). Six consecutive $4 \mu \mathrm{m}$-thick sections were taken at the largest longitudinal diameter of each bulb and then stained with hematoxylin and eosin. The most representative sections were selected by standard light microscopy (Light Microscope BX43, OLYMPUS Europa SE \& CO, Hamburg, Germany). The morphological analysis of the retina was performed using the UltraFast Scanner (Philips IntelliSite Solution, Best, The Netherlands) with DigiPath ${ }^{\mathrm{TM}}$ Professional Production Software (Xerox, Norwalk, CT, USA). 
In the morphological examination, the following qualitative and quantitative parameters were selected for the examination: longitudinal diameter of the eye (um) (optic nerve-to-cornea), lateral diameter of the eye (um) (cornea-cornea), retinal thickness as mean of three consecutive measurements around the optic nerve (um), retinal thickness/eye longitudinal diameter ratio, retinal lateral thickness/eye longitudinal diameter ratio, retinal inflammation presence (YES/NO), retinal fibroblast reaction presence (YES/NO), signs of retinal degeneration (YES/NO), retinal neovascularization (YES/NO) [11-16].

\subsection{Immunohistochemistry}

The immunohistochemical expression of WFS1 (Wolfram Syndrome Protein 1), GFAP (Glial Fibrillary Acidic Protein) and NSE (Neuron Specific Enolase) was evaluated following the standard protocol $[17,18]$. To perform specific staining, the eyeballs were cut into $5 \mu \mathrm{m}$ thick cross-sections (Accu-Cut SMR 200 rotary microtome, Sakura Finetek, Tokyo, Japan) and collected on polylysine-covered microscopic slides. The specimens were tested for antibody presence: for WFS1 (Catalog number: 11558-1-AP, Immunogen Catalog Number: AG2114, WFS1 Polyclonal Rabbit Antibody, Proteintech Group Inc, Rosemont, IL, USA), for GFAP (M0761, Clone GF2, Monoclonal Mouse Anti-Human with cross-reactivity to mice, Dako-Agilent, San Jose, CA, USA), for NSE (Clone BBS/NC/VI-H14, Monoclonal Mouse Anti-Human with cross-reactivity to mice, Dako-Agilent, San Jose, CA, USA). GFAP and NSE antigens were unmasked by incubating the sections in pH 8.0 citrate buffer (S1699, Dako-Agilent, San Jose, CA, USA) in PT-link (Dako-Agilent, San Jose, CA, USA) for $20 \mathrm{~min}$ at $97^{\circ} \mathrm{C}$. The WFS1 antigen was unmasked by incubating the sections in pH 6.0 citrate buffer (S1699, Dako-Agilent, San Jose, CA, USA) in a water bath for $30 \mathrm{~min}$ at $98^{\circ} \mathrm{C}$. The visualization of the result was done using specific detection systems-EnVisionTM FLEX+ (Dako-Agilent, San Jose, CA, USA). The reactions were carried out using the Autostainer Link (Dako-Agilent, San Jose, CA, USA). For the detection of the antibody, EnVision+ System-HRP with DAB as a chromogen (K4011, Dako-Agilent, San Jose, CA, USA) were used according to the instructions of the manufacturer. Nuclei were counterstained with hematoxylin.

The stained sections were evaluated qualitatively under light microscopy (Light Microscope BX43, OLYMPUS Europa SE \& CO, Hamburg, Germany). Representative images were taken using UltraFast Scanner (Philips IntelliSite Solution, Eindhoven, The Netherlands) with DigiPath ${ }^{\mathrm{TM}}$ Professional Production Software (Xerox, Norwalk, CT, USA).

\subsection{Statistical Analysis}

For the statistical calculations of the histopathological examination results, each eye from each analyzed group was treated separately, but without a division into right and left eyes. Therefore, six measurements were obtained in both the study and control groups.

Continuous variables were presented as medians followed by interquartile ranges (IQR), while nominal variables were presented as numbers followed by percentages in brackets. The ShapiroWilk test was used to assess the normality of distribution. Continuous variables were compared using the Mann-Whitney U-test in the case of a non-normal distribution or t-test in the case of normal distribution. The Statistica 12.5 PL package (Statsoft, Tulsa, OK, USA) was used for the analysis. $p$ values $<0.05$ were considered statistically significant.

\section{Results}

\subsection{Morphometric Analysis of Mice Retinal Thickness and Morphology}

The mean longitudinal diameter of the eye and the lateral diameter of the eye in the Wfs1KO group were $2921 \pm 125 \mu \mathrm{m}$ and $2616 \pm 172 \mu \mathrm{m}$, respectively. The corresponding values in the Wfs1WT mice group were $2868 \pm 63 \mu \mathrm{m}$ and $2608 \pm 111 \mu \mathrm{m}$, respectively. These values did not differ between groups. 
The mean central retinal thickness was slightly thinner in Wfs1KO as compared to the Wfs1WT mice ( $235 \pm 8 \mu \mathrm{m}$ vs. $244 \pm 5 \mu \mathrm{m}, p=0.058$, respectively). The retinal thickness/longitudinal diameter ratio in the Wfs $1 \mathrm{KO}$ mice was significantly lower compared to the Wfs $1 \mathrm{WT}$ mice $(0.081 \pm 0.003 \mathrm{vs}$. $0.085 \pm 0.003, p=0.035$, respectively), whereas the lateral retinal thickness/lateral diameter ratio was only marginally lower $0.048 \pm 0.003$ vs. $0.051 \pm 0.003, p=0.11$, respectively). These results are illustrated in Figure 1A,B.

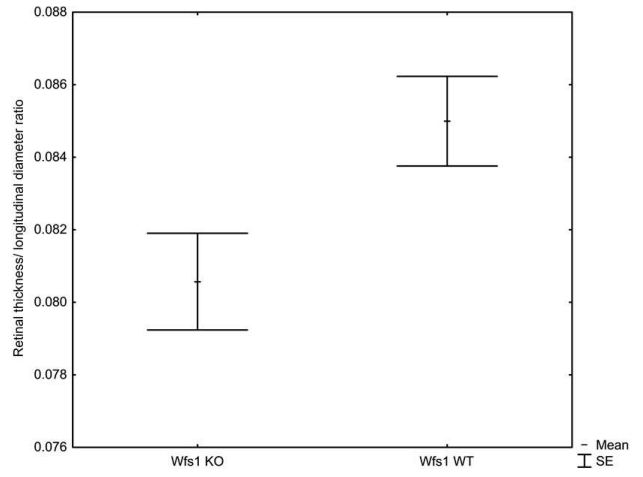

(A)

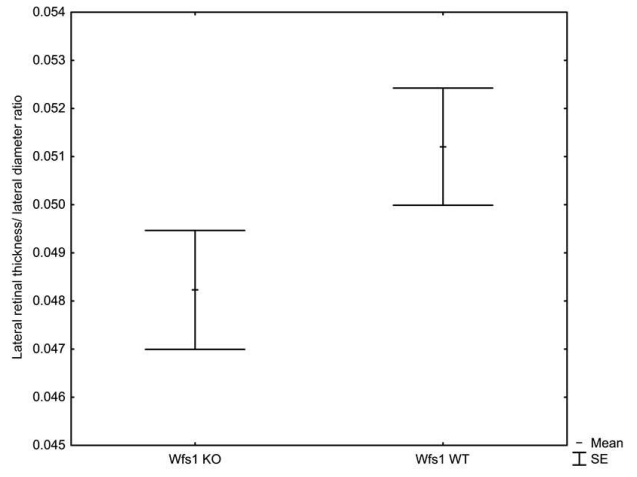

(B)

Figure 1. Box-and-whiskers plot of the mean retinal thickness/longitudinal diameter ratio (A) and the lateral retinal thickness/lateral diameter ratio (B) in the Wfs1KO and Wfs1WT mice, Mann-Whitney $U$ test. Abbreviations: Wfs1KO: Wolfram syndrome 1 gene knockout mice; Wfs1WT: Wolfram syndrome 1 gene wild-type mice.

The comparative analysis of $\mathrm{Wfs} 1 \mathrm{KO}$ and $\mathrm{Wfs} 1 \mathrm{WT}$ mouse retina $(\mathrm{H} \& \mathrm{E})$ images revealed significant histomorphological differences in all the retinal layers between samples (Figure 2).
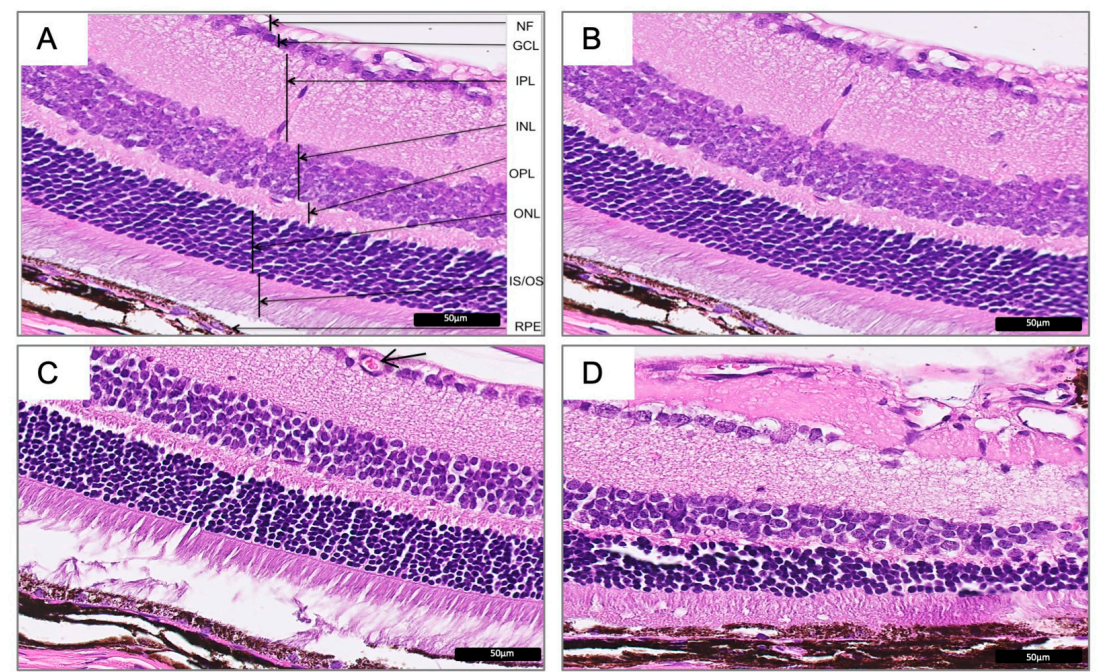

Figure 2. Hematoxylin and eosin images representing normal mice retina in Wfs1-wild-type mice $(\mathbf{A}, \mathbf{B})$ and the corresponding representative images of the defect mice retina in the Wfs1-mutated mice (C,D). The neovascularization (C, arrow) and morphological (D) defects can be seen. Magnification of 400X. Abbreviations: Wfs1: Wolfram syndrome 1 gene mice; NF: nerve fiber layer; GCL: ganglion cell layer; IPL: inner plexiform layer; INL: inner nuclear layer; OPL: outer plexiform layer; ONL: outer nuclear layer-representing photoreceptor cell bodies; IS/OS: inner segment/outer segment; RPE: retinal pigment epithelium. 
In all Wfs1KO cases, the inner and outer retina did show significant abnormalities. There were observable loosely arranged cells junctions, a disordered arrangement of cells in each layer and a reduced thickness of segments.

In four (67\%) eyeballs of Wfs1KO mice, the intra-retinal neovessels in ganglion cell layer (GCL) was observed. The vessel dilation or microaneurysms were found in three animals. None of these findings were seen among the Wfs1WT mice (Figure 2C).

No symptoms of retinal inflammation and retinal fibroblast reaction in any of the analyzed subgroups were observed. Seven eyeballs showed symptoms of retinal degeneration (two eyeballs of Wfs1WT mice and five eyeballs of Wfs1KO mice).

\subsection{Immunohistochemistry Analysis}

In this study, performed on the mouse model of the Wolfram syndrome, we confirmed that the wolframin protein is not expressed in retina of Wfs1KO mice when compared to mice with the normal Wfs1 gene (Wfs1WT) (Figure 3A,B). Moreover, the staining for GFAP as a neuronal marker showed nerve degeneration in Wfs1KO mice, confirming that this mouse model presented similar ophthalmological features to these observed among patients with WFS (Figure 4).
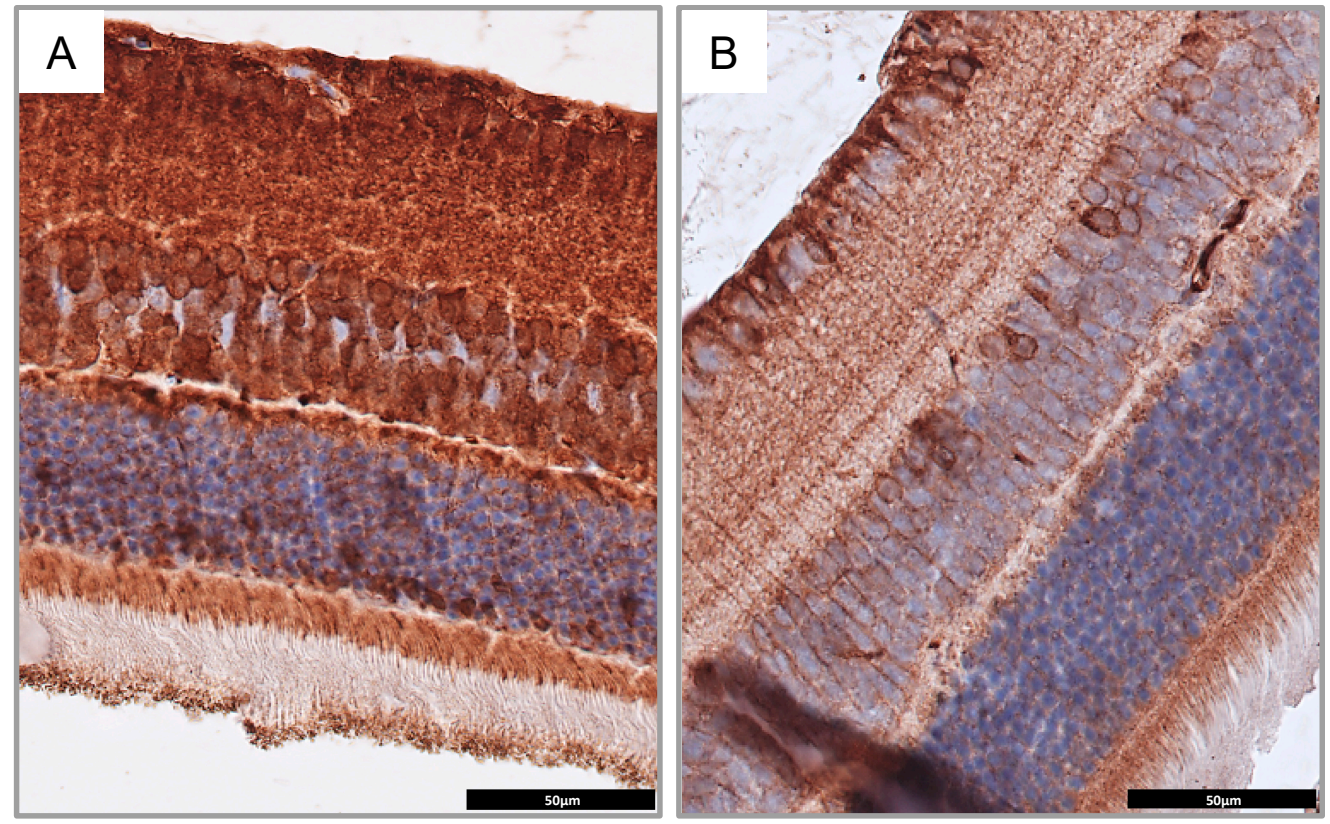

Figure 3. Immunohistochemical staining for wolframin in Wfs1-wild-type mice (A) and Wfs1-mutated mice (B) showing significantly less intensive staining in the latter. Magnification of 400x. Abbreviations: Wfs1, Wolfram syndrome 1 gene mice.

The Wfs1KO mice had significantly fewer GFAP-positive cells than the Wfs1WT animals. All the GFAP-positive cells in the Wfs1KO group had a lower staining intensity than the controls. The distribution of the GFAP immunoreactivity in both analyzed groups of mice was located in the same retinal layers: in the nerve fiber (NF), ganglion cell (GCL), inner plexiform (IPL), inner nuclear (INL), outer plexiform (OPL), and outer nuclear (ONL) layers-representing the ganglion cell nerve fibers, ganglion cells, amacrine cells, horizontal cells, photoreceptor cell bodies layers as well as the Müller glial cells, astrocytes and microglia. However, a significantly lower number of GFAP positive cells in the inner nuclear layer in Wfs1KO retinas was observed (Table 1, Figure 4). 

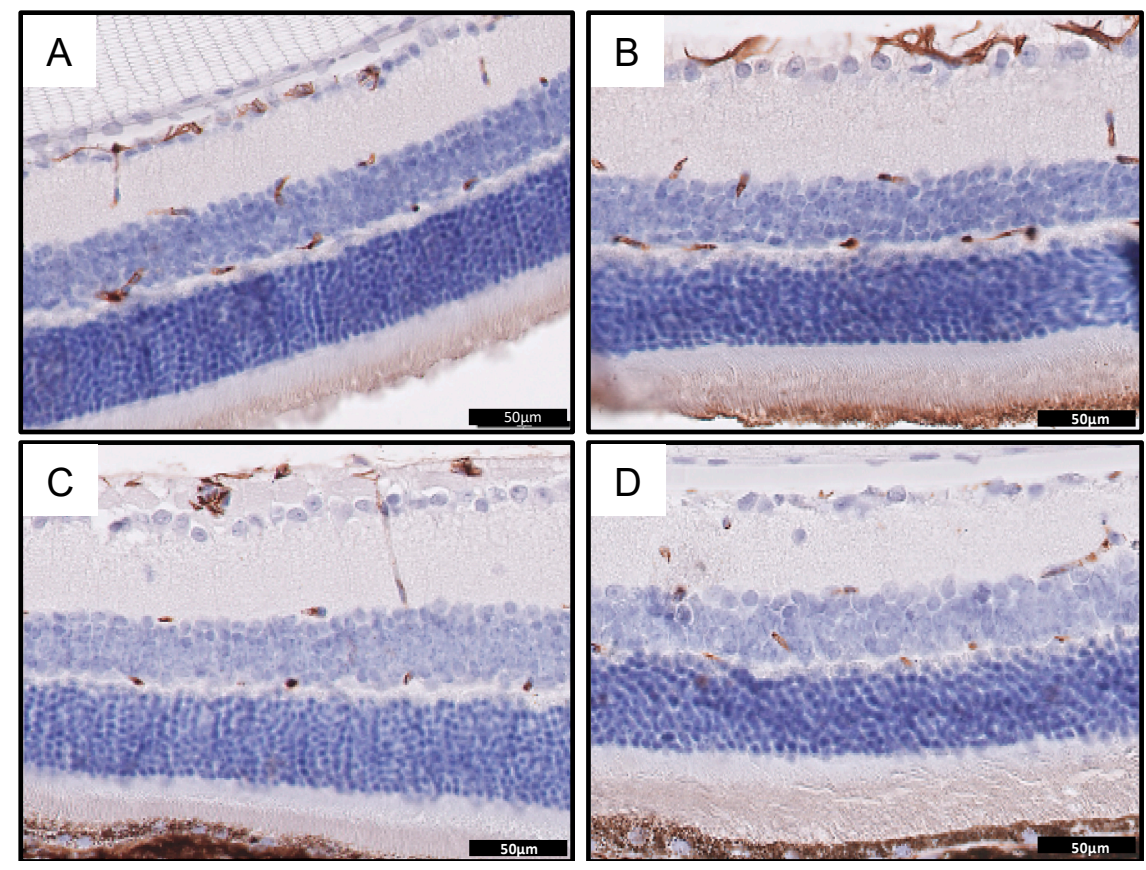

Figure 4. Immunohistochemical staining for glial fibrillary acidic protein (GFAP) showing retinal neuronal network in normal mice retina in Wfs1-wild-type mice $(\mathbf{A}, \mathbf{B})$ and the corresponding representative images of neuronal retinal defects in the Wfs1-mutated mice (C,D). Fewer neurons positive for GFAP can be seen in (C,D). Magnification of 400X. Abbreviations: GFAP: glial fibrillary acidic protein; $W f s 1$ : Wolfram syndrome 1 gene mice.

Table 1. Morphometric analysis of the mice retinal thickness and morphology in the Wfs1KO and Wfs1WT mice. Abbreviations: Wfs1KO: Wolfram syndrome 1 gene knockout mice; Wfs1WT: Wolfram syndrome 1 gene wild-type mice; GFAP: glial fibrillary acidic protein.

\begin{tabular}{|c|c|c|c|}
\hline Characteristics & Wfs1KO Male Mice & Wfs1WT Male Mice & $p$-Level * \\
\hline Analyzed eyeballs/animals & $N=6 / N=3$ & $N=6 / N=3$ & NA \\
\hline Longitudinal diameter of eye $(\mu \mathrm{m})$ & $2921 \pm 125$ & $2868 \pm 63$ & 0.376 \\
\hline Lateral diameter of eye $(\mu \mathrm{m})$ & $2616 \pm 172$ & $2608 \pm 111$ & 0.927 \\
\hline Retinal thickness $(\mu \mathrm{m})$ & $235.2 \pm 8.0$ & $243.7 \pm 5.5$ & 0.058 \\
\hline Retinal thickness/longitudinal diameter ratio & $0.081 \pm 0.003$ & $0.085 \pm 0.003$ & 0.035 \\
\hline Lateral retinal thickness $(\mu \mathrm{m})$ & $125.8 \pm 4.1$ & $133.7 \pm 11.5$ & 0.135 \\
\hline Vessel dilation or microaneurysms & $4 / 3$ & $0 / 6$ & 0.11 \\
\hline GFAP positive cells in inner nuclear layer (cells/100 $\mu^{2}$ ) & $2.9 \pm 0.3$ & $3.8 \pm 0.4$ & 0.042 \\
\hline
\end{tabular}

* significant difference according to the nonparametric tests. NA, not applicable.

\section{Discussion}

Previous studies on the ocular wolframin expression were focused in healthy human and animal models. The presence of wolframin in the retinas including retinal pigment epithelium, retinal ganglion cells, optic axons and the proximal optic nerve has been proven.

To the best our knowledge, there is only one study investigating the wolframin expression in the Wfs1KO mice retinas in the literature. The described study was carried out on mice in which the exon 2 was modified [19].

Human studies have revealed that the WFS1 gene mutations are mostly located in exon 8 and the sequence first exon 8 for molecular diagnosis seems to be the most appropriate [20]. In this study we used mice with the exon 8 modified in the age of 3 months. At this age, Wfs1KO animals already display a characteristic phenotype for the WFS [21].

The results of our experimental studies on the Wolfram syndrome mouse model confirm our previous like optical coherence tomographic (OCT) results in WFS patients. We have previously 
described that the average retinal thickness decreases with the progression of the disease. An important observation was that the average retinal thickness and total retinal volume of the OCT parameters in the WFS patients have been decreasing slower than the retinal nerve fiber layer (RNFL) value [2]. Analyzing the results of the present study on Wfs1KO mice we can explain this phenomenon by the fact that intercellular connections are loosened in all the nerve layers of the retina and therefore, despite significant nerve cell degeneration, the average retina thickness may decrease more slowly. As in humans, we saw a significant reduction of retinal thickness/longitudinal diameter ratio in the Wfs1KO mice compared to the WT littermates.

A surprising observation for us was finding retinal neovascularization in $67 \%$ of the Wfs $1 \mathrm{KO}$ mouse retinas. According to our knowledge, only three studies report the occurrence of diabetic retinopathy in WFS patients [22-24].

Present molecular knowledge of the WFS allows for the statement that wolframin-as a product of the WFS1 gene-is an integral component of the endoplasmic reticulum (ER). The loss of WFS1 leads to neurodegeneration through apoptosis due to increased ER stress, which is generally considered to induce oxidative stress [3,25]. It is well known that inflammation, oxidative stress, and neuronal dysfunction are also contributing to the pathogenesis of ischemic retinal diseases [26]. The most widely used model to study retinal ischemic diseases is the mouse oxygen-induced retinopathy (OIR) model [27]. In addition to angiogenesis disorders in OIR, neuronal damage has also been observed and pathological effects on the retinal glia have also been reported [28]. The interaction between pathologic retinal angiogenesis and retinal glial dysfunction plays a key role in the progression of OIR [29]. Retinal astrocytes, which are located in the layer of nerve fibers, are critical for the proper development of retinal vessels. Since retinal astrocytes are damaged in the retina of the OIR model, their VEGF-A secretion causes pathological neovascularization [30]. In the retina of the eye of the mouse, in response to the injury caused by ischemia, the amount of microglia increases [31] and plays an important role in organizing blood vessel formation [32].

Our results are concordant with the previous studies of the OIR mouse model because we also observed that microglial cells in the GFAP staining were attached to the neovascular tufts. Therefore, among the causes of observed retinal neovascularization in our Wfs1KO mice, should be considered the consequences of chronic ER stress and neurodegeneration, but we cannot exclude hyperglycemia, as in classical diabetic retinopathy. Unfortunately, in our study we did not perform a glycemic test.

Our study has some limitations. Most importantly, it was performed on a small number of Wfs1KO mice eyes. In addition, the lack of long-term studies of Wfs1KO mice at different ages and thus at different stages of the disease prevented us from observing the time of retinal thickness changes appearance. Our detailed histological analyses using the quantitative morphometry of the mouse retina could be enriched by in vivo functional tests like optical coherence tomographic (OCT) imaging, fluorescein angiography (FA) and electroretinographic (ERG) examinations.

Author Contributions: Conceptualization, W.M., A.W. and A.Z.; methodology, A.W.; A.Z., M.B., P.J., M.I. and S.K.; analysis and interpretation of the data, W.M., A.W., A.Z., and M.B.; statistical analysis, W.M.; writing-original draft preparation, A.W.; writing-review and editing, W.M. All authors have read and agreed to the published version of the manuscript.

Funding: This study is supported by the National Science Centre Poland, grant No. 2014/15/B/NZ5/01579.

Acknowledgments: We thank Synevo Sp. z o.o. Company (HQ, Warsaw, Poland) for providing access to the UltraFast Scanner and DigiPath ${ }^{\mathrm{TM}}$ Professional Production Software. We thank Radzislaw Kordek (Medical University of Lodz, Poland) for expert consultation in pathological assessments.

Conflicts of Interest: The authors declare no conflict of interest.

\section{References}

1. Barrett, T.G.; Bundey, S.; MacLeod, A. Neurodegeneration and diabetes: UK nationwide study of Wolfram (DIDMOAD) syndrome. Lancet 1995, 346, 1458-1463. [CrossRef] 
2. Zmyslowska, A.; Fendler, W.; Waszczykowska, A.; Niwald, A.; Borowiec, M.; Jurowski, P.; Mlynarski, W. Retinal thickness as a marker of disease progression in longitudinal observation of patients with Wolfram syndrome. Acta Diabetol. 2017, 54, 1019-1024. [CrossRef] [PubMed]

3. Ishihara, H.; Takeda, S.; Tamura, A.; Takahashi, R.; Yamaguchi, S.; Takei, D.; Yamada, T.; Inoue, H.; Soga, H.; Katagiri, H.; et al. Disruption of the WFS1 gene in mice causes progressive -cell loss and impaired stimulus-secretion coupling in insulin secretion. Hum. Mol. Genet. 2004, 13, 1159-1170. [CrossRef] [PubMed]

4. Luuk, H.; Kõks, S.; Plaas, M.; Hannibal, J.; Rehfeld, J.F.; Vasar, E. Distribution of Wfs1 protein in the central nervous system of the mouse and its relation to clinical symptoms of the Wolfram syndrome. J. Comp. Neurol. 2008, 509, 642-660. [CrossRef]

5. Riggs, A.C.; Bernal-Mizrachi, E.; Ohsugi, M.; Wasson, J.; Fatrai, S.; Welling, C.; Murray, J.; Schmidt, R.E.; Herrera, P.L.; Permutt, M.A. Mice conditionally lacking the Wolfram gene in pancreatic islet beta cells exhibit diabetes as a result of enhanced endoplasmic reticulum stress and apoptosis. Diabetologia 2005, 48, 2313-2321. [CrossRef]

6. Kõks, S.; Soomets, U.; Payá-Cano, J.L.; Fernandes, C.; Luuk, H.; Plaas, M.; Terasmaa, A.; Tillmann, V.; Noormets, K.; Vasar, E.; et al. Wfs1 gene deletion causes growth retardation in mice and interferes with the growth hormone pathway. Physiol. Genom. 2009, 37, 249-259. [CrossRef]

7. Waszczykowska, A.; Zmysłowska, A.; Braun, M.; Zielonka, E.; Ivask, M.; Koks, S.; Jurowski, P.; Młynarski, W. Corneal Abnormalities Are Novel Clinical Feature in Wolfram Syndrome. Am. J. Ophthalmol. 2020, 217, 140-151. [CrossRef]

8. Zmysłowska, A.; Fendler, W.; Niwald, A.; Ludwikowska-Pawlowska, M.; Borowiec, M.; Antosik, K.; Szadkowska, A.; Młynarski, W. Retinal Thinning as a Marker of Disease Progression in Patients With Wolfram Syndrome. Diabetes Care 2015, 38, 36-37. [CrossRef]

9. Zmysłowska, A.; Waszczykowska, A.; Baranska, D.; Stawiski, K.; Borowiec, M.; Jurowski, P.; Fendler, W.; Mlynarski, W. Optical coherence tomography and magnetic resonance imaging visual pathway evaluation in Wolfram syndrome. Dev. Med. Child Neurol. 2018, 61, 359-365. [CrossRef]

10. Dutta, S.; Sengupta, P. Men and mice: Relating their ages. Life Sci. 2016, 152, 244-248. [CrossRef]

11. Söker, T.; Dalke, C.; Puk, O.; Floss, T.; Becker, L.; Bolle, I.; Favor, J.; Hans, W.; Hölter, S.M.; Horsch, M.; et al. Pleiotropic effects in Eya3 knockout mice. BMC Dev. Biol. 2008, 8, 118. [CrossRef]

12. Jun, A.S.; Meng, H.; Ramanan, N.; Matthaei, M.; Chakravarti, S.; Bonshek, R.; Black, G.C.; Grebe, R.; Kimos, M. An alpha 2 collagen VIII transgenic knock-in mouse model of Fuchs endothelial corneal dystrophy shows early endothelial cell unfolded protein response and apoptosis. Hum. Mol. Genet. 2011, 21, 384-393. [CrossRef] [PubMed]

13. Zhu, L.; Shen, J.; Zhang, C.; Park, C.Y.; Kohanim, S.; Yew, M.; Parker, J.S.; Chuck, R.S. Inflammatory cytokine expression on the ocular surface in the Botulium toxin B induced murine dry eye model. Mol. Vis. 2009, 15, 250-258. [PubMed]

14. Cole, N.; Hume, E.B.; Jalbert, I.; Vijay, A.K.; Krishnan, R.; Willcox, M.D. Effects of topical administration of 12-methyl tetradecanoic acid (12-MTA) on the development of corneal angiogenesis. Angiogenesis 2007, 10, 47-54. [CrossRef] [PubMed]

15. Jeon, C.-J.; Strettoi, E.; Masland, R.H. The Major Cell Populations of the Mouse Retina. J. Neurosci. 1998, 18, 8936-8946. [CrossRef]

16. Remtulla, S.; Hallett, P. A schematic eye for the mouse, and comparisons with the rat. Vis. Res. 1985, 25, 21-31. [CrossRef]

17. Bielska, M.; Borowiec, M.; Jesionek-Kupnicka, D.; Braun, M.; Bojo, M.; Pastorczak, A.; Kalinka-Warzocha, E.; Prochorec-Sobieszek, M.; Robak, T.; Warzocha, K.; et al. Polymorphism in IKZF1 gene affects clinical outcome in diffuse large B-cell lymphoma. Int. J. Hematol. 2017, 106, 794-800. [CrossRef]

18. Jesionek-Kupnicka, R.; Braun, M.; Trabska-Kluch, B.; Czech, J.; Szybka, M.; Szymańska, B.; Kulczycka-Wojdala, M.; Bieńkowski, M.; Kordek, R.; Zawlik, I. MiR-21, miR-34a, miR-125b, miR-181d and miR-648 levels inversely correlate with MGMT and TP53 expression in primary glioblastoma patients. Arch. Med Sci. 2017, 15, 504-512. [CrossRef]

19. Wersinger, D.B.; Benkafadar, N.; Jagodzinska, J.; Hamel, C.; Tanizawa, Y.; Lenaers, G.; Delettre, C. Impairment of Visual Function and Retinal ER Stress Activation in Wfs1-Deficient Mice. PLoS ONE 2014, 9, e97222. [CrossRef] 
20. Hardy, C.; Khanim, F.; Torres, R.; Scott-Brown, M.; Seller, A.; Poulton, J.; Collier, D.; Kirk, J.; Polymeropoulos, M.; Latif, F.; et al. Clinical and Molecular Genetic Analysis of 19 Wolfram Syndrome Kindreds Demonstrating a Wide Spectrum of Mutations in WFS1. Am. J. Hum. Genet. 1999, 65, 1279-1290. [CrossRef]

21. Tein, K.; Kasvandik, S.; Kõks, S.; Vasar, E.; Terasmaa, A. Prohormone convertase 2 activity is increased in the hippocampus of Wfs1 knockout mice. Front. Mol. Neurosci. 2015, 8, 45. [CrossRef]

22. Gupta, K.L.; Ghosh, A.K.; Jha, V.; Gupta, A.; Sakhuja, V. Wolfram (DIDMOAD) syndrome with diabetic retinopathy. J. Assoc. Physicians India 1994, 42, 831-832.

23. Lim, M.C.; Thai, A.C. A Chinese family with Wolfram syndrome presenting with rapidly progressing diabetic retinopathy and renal failure. Ann. Acad. Med. Singap. 1990, 19, 548-555.

24. Barrett, T.G.; Bundey, S.E.; Fielder, A.R.; Good, P.A. Optic atrophy in Wolfram (DIDMOAD) syndrome. Eye 1997, 11, 882-888. [CrossRef]

25. Hofmann, S.; Philbrook, C.; Gerbitz, K.-D.; Bauer, M.F. Wolfram syndrome: Structural and functional analyses of mutant and wild-type wolframin, the WFS1 gene product. Hum. Mol. Genet. 2003, 12, 2003-2012. [CrossRef]

26. Vähätupa, M.; Nättinen, J.; Jylhä, A.; Aapola, U.; Kataja, M.; Kööbi, P.; Järvinen, T.A.; Uusitalo, H.; Uusitalo-Järvinen, H. SWATH-MS Proteomic Analysis of Oxygen-Induced Retinopathy Reveals Novel Potential Therapeutic Targets. Investig. Opthalmol. Vis. Sci. 2018, 59, 3294-3306. [CrossRef]

27. E Smith, L.; Wesolowski, E.; McLellan, A.; Kostyk, S.K.; D'Amato, R.; Sullivan, R.; A D'Amore, P. Oxygen-induced retinopathy in the mouse. Investig. Ophthalmol. Vis. Sci. 1994, 35, 101-111.

28. Vessey, K.; Wilkinson-Berka, J.L.; Fletcher, E.L.; Wilkinson-Berka, J. Characterization of retinal function and glial cell response in a mouse model of oxygen-induced retinopathy. J. Comp. Neurol. 2010, 519, 506-527. [CrossRef]

29. Xu, Y.; Lu, X.; Hu, Y.; Yang, B.; Tsui, C.-K.; Yu, S.; Lu, L.; Liang, X. Melatonin attenuated retinal neovascularization and neuroglial dysfunction by inhibition of HIF-1 $\alpha$-VEGF pathway in oxygen-induced retinopathy mice. J. Pineal Res. 2018, 64, e12473. [CrossRef]

30. Karlstetter, M.; Scholz, R.; Rutar, M.; Wong, W.T.; Provis, J.A.N.M.; Langmann, T. Retinal microglia: Just bystander or target for therapy? Prog. Retin. Eye Res. 2015, 45, 30-57. [CrossRef]

31. Davies, M.H.; Eubanks, J.P.; Powers, M.R. Microglia and macrophages are increased in response to ischemia-induced retinopathy in the mouse retina. Mol. Vis. 2006, 12, 467-477. [PubMed]

32. Checchin, D.; Sennlaub, F.; Levavasseur, E.; LeDuc, M.; Chemtob, S. Potential Role of Microglia in Retinal Blood Vessel Formation. Investig. Opthalmol. Vis. Sci. 2006, 47, 3595-3602. [CrossRef] [PubMed] 